\title{
Clinical Study \\ Dickkopf-1 Expression Is a Novel Prognostic Marker for Gastric Cancer
}

\author{
Chengcheng Gao, Rui Xie, Chengcheng Ren, and Xiaozhong Yang \\ Department of Gastroenterology, Huai'an No.1 Hospital, Nanjing Medical University, Huai'an, Jiangsu 223300, China \\ Correspondence should be addressed to Chengcheng Ren, gao.jsha@gmail.com
}

Received 14 September 2011; Revised 6 November 2011; Accepted 23 November 2011

Academic Editor: Settara Chandrasekharappa

Copyright ( $) 2012$ Chengcheng Gao et al. This is an open access article distributed under the Creative Commons Attribution License, which permits unrestricted use, distribution, and reproduction in any medium, provided the original work is properly cited.

\begin{abstract}
Aim. To investigate the involvement of Dickkopf-1 expression in gastric cancer. Methods. Dickkopf-1 mRNA and protein expression were determined by real-time quantitative reverse transcriptase-polymerase chain reaction (qRT-PCR) and immunohistochemistry in specimens of primary cancer and their adjacent noncancerous tissues in gastric cancer patients. Results. Dickkopf-1 mRNA and protein expression levels were both significantly upregulated in gastric cancer lesions compared with adjacent noncancerous tissues. Its positive expression was correlated with depth of invasion, vessel invasion, lymph node and distant metastasis, and TNM stage of tumors. Additionally, in stages I, II, and III gastric cancers, the 5- year survival rate of patients with a high expression of Dickkopf-1 was significantly lower than that in patients with low expression. In stage IV, Dickkopf1 expression did not correlate with the 5-year survival rate. Further multivariate analysis suggested that the up-regulation of Dickkopf-1 was an independent prognostic indicator for gastric cancer. Conclusion. A subset of cases with gastric cancer revealed the up-regulation of Dickkopf-1, which was associated with a progressive pathological feature and an aggressive clinical course. Therefore, Dickkopf-1 expression may be predictor for poor prognosis in patients with gastric cancer. This is the first report describing the involvement of Dickkopf-1 in gastric cancer.
\end{abstract}

\section{Introduction}

Gastric cancer is one of the most frequently diagnosed malignant neoplasms and has the second-highest cancer-related mortality rate in the world [1]. In East Asia especially, like China, Japan, and Korea, more than one million new cases are diagnosed each year [2]. Most patients with gastric cancer are diagnosed at advanced clinical stages with a high ratio of lymph node metastasis. Despite a curative operation and postoperative adjuvant therapy, nearly $60 \%$ of those patients succumb to the disease [3]. The genetic bases underlying gastric tumorigenesis and progression are still largely unknown. Currently, the tumor $(\mathrm{T})$ node $(\mathrm{N})$ metastasis $(\mathrm{M})$ stage is still the most important prognostic factor for gastric cancer. However, the prognosis varies among patients in the same stage. Therefore, it is very important to find novel factors for the early diagnostic and prognostic evaluation of gastric cancer.
Human Dickkopf-1 is a member of the Dickkopf gene family, which is composed of Dickkopf-1, Dickkopf-2, Dickkopf-3, and Dickkopf-4, together with a unique Dickkopf-3-related protein termed Soggy [4]. Several recent studies have also implicated members of the Dickkopf family of Wnt inhibitors in suppression of human cancer. Reduced levels of Dickkopf-3 were found in prostate, lung cancers, renal clear cell carcinoma [5]. Overexpression of Dickkopf1 or Dickkopf-3 resulted in inhibition of cell tumorigenicity, cell motility, and invasiveness [6]. Recently it has been demonstrated that expression of Dickkopf-1, -2, and -3 is reduced in most of melanoma cell lines and most of tumor samples [7]. Among the members of the Dickkopf family, Dickkopf-1 is a $35-\mathrm{kDa}$ secreted protein involved in embryonic development and known as a potent inhibitor of the Wnt signaling pathway, which plays a critical role in cell patterning, proliferation, and fate determination during embryogenesis [8]. It has been shown that the 
Dickkopf-1 gene has a restricted expression in placenta and mesenchymal stem cells only, but not in other normal tissues [9]. Recent studies suggest an inhibition of neoplastic cell transformation by activation of Dickkopf-1 expression. It has demonstrated that Dickkopf-1 was downregulated in human tumors, indicating that it might act as a tumor suppressor. For example, Mikheev et al. showed that Dickkopf-1 activates cell death in melanoma cells [10]. Kuphal et al. reported that the expression of Dickkopf-1 is strongly reduced in human melanoma cell lines [11]. Lee et al. suggested that Dickkopf-1 was responsible for the inhibition of cell growth and induction of apoptosis in human mesothelioma cells [12]. Mikheev et al. demonstrated that Dickkopf-1 suppressed the tumorigenicity of two human breast cancer cell lines that also lack an activated Wnt signaling [13]. However, Dickkopf-1 overexpression was also found in some human cancers. Dickkopf- 1 was found in 26 out of 32 human hepatoblastomas and 5 out of 6 cases of Wilms' tumor [14]. The expression of Dickkopf-1 was also elevated in 21 out of 73 cases of breast cancer, in particular hormoneresistant breast tumors [15]. Additionally, gene expression profiles revealed that Dickkopf-1 was overexpressed in prostatic, lung, esophageal, and hepatic carcinoma, serving as a serologic and prognostic biomarker [16]. Wang and Zhang also reported that Dickkopf-1 is frequently overexpressed in ovarian serous carcinoma and involved in tumor invasion [17]. These studies suggested that Dickkopf- 1 is associated with the tumorigenesis and tumor progression. To our knowledge, the role of Dickkopf-1 expression in gastric cancer was rarely studied. To address this problem, in this study, we examined the expression of Dickkopf- 1 in surgical specimens of gastric cancer to explore the possible correlation between Dickkopf-1 expression and clinicopathological variables and to determine its prognostic value.

\section{Materials and Methods}

2.1. Patients and Tissue Samples. This study was approved by the Research Ethics Committee of Huai'an No.1 Hospital, China. Informed consent was obtained from all of the patients. All specimens were handled and made anonymous according to the ethical and legal standards.

Gastric cancer tissues were collected from the gastrectomy specimens of 328 patients (235 male, 93 female; median age $=60.0$ years; range $=28 \sim 92$ years) treated at the Department of Surgery, Huai'an No.1 Hospital, between March 2000 and March 2005. Tissues were formalin fixed, paraffin embedded, and clinically and histopathologically diagnosed at the Departments of Gastrointestinal Surgery and Pathology. All patients had follow-up records for over 5 years. The follow-up deadline was October 2010. The survival time was counted from the date of surgery to the follow-up deadline, or date of death (usually the result of cancer recurrence or metastasis). According to the WHO histological classification of gastric cancer formulated in 2002, there were 245 tubular adenocarcinomas, 12 papillary adenocarcinomas, 22 mucinous adenocarcinomas, and 49 signet-ring cell carcinomas. Nine were highly differentiated adenocarcinomas, 96 were well- or moderately differentiated adenocarcinomas, 220 were poorly differentiated, and 3 were undifferentiated adenocarcinomas. There were 46 cases with distant metastasis. Sixty-eight cases were categorized as stage I, 78 as stage II, 130 as stage III, and 52 as stage IV. Three hundred and twenty-eight noncancerous human gastric tissues were obtained from gastrectomy of adjacent gastric cancer margins (greater than $5 \mathrm{~cm}$ ). Routine chemotherapy was given after surgery to patients with advanced-stage disease, but none of the patients received radiation treatment. The clinical and pathologic parameters were obtained from the pathological reports and presented in Table 1.

\subsection{Real-Time Quantitative Reverse Transcriptase-Polymerase} Chain Reaction. Real-time quantitative reverse transcriptase-polymerase chain reaction (qRT-PCR) was performed to detect the expression of Dikkopf-1 mRNA in 20 pairs of human gastric cancer and adjacent noncancerous human gastric tissues. Total RNA was isolated from human gastric cancer and adjacent noncancerous human gastric tissues by an RNeasy Mini kit (QIAGEN). Random-primed cDNA synthesis was performed using QuantiTect Reverse Transcription Kit (QIAGEN). QRT-PCR was performed using a PTC-1000 programmable thermal controller (MJ Research,Waltham, MA, USA) with QuantiTect SYBR Green PCR kit (QIAGEN, Valencia, CA, USA) according to the manufacturer's instructions. For amplifications, the following primers were designed: Dikkopf-1: forward, $5^{\prime}$-AGA CCA TTG ACAACT ACC AGC CGT-3'; reverse, 5' -TCT GGA ATA CCC ATC CAA GGT GCT- $3^{\prime}$ and GAPDH: forward, $5^{\prime}$-CCT CCG GGA AAC TGT GGC GTG ATG G-3'; reverse, $5^{\prime}$-AGA CGG CAG GTC AGG TCC ACC ACT G-3'. Each sample was examined in triplicate, and the amounts of the PCR products were nonneoplasticized to GAPDH which served as internal control.

2.3. Western Blotting. To confirm the specificity of the antiDickkopf-1 antibody, western blotting test was carried out. Human gastric cancer tissues were lysed in $100 \mu \mathrm{L}$ lysis buffer (50 mM Tris-HCL pH 7.4, $125 \mathrm{mM} \mathrm{NaCl}, 0.1 \%$ (v/v) NP-40, $5 \mathrm{mM}$ ethylene diamine tetraacetic acid (EDTA), $50 \mathrm{mM} \mathrm{NaF}$, $50 \mu \mathrm{g} / \mathrm{mL}$ phenylmethylsulfonyl fluoride (PMSF), $10 \mu \mathrm{g} / \mathrm{mL}$ leupeptin, $10 \mu \mathrm{g} / \mathrm{mL}$ soybean trypsin inhibitor, and $1 \mu \mathrm{g} / \mathrm{mL}$ aprotinin] on ice for $10 \mathrm{~min})$. Protein $(50 \mu \mathrm{g})$ was subjected to western blot analysis. Anti-Dickkopf-1 polyclonal antibody (Santa Cruz Biotechnology, Santa Cruz, CA, USA) was used in primary reaction. Bands were visualized by employing the enhanced chemiluminescence (ECL) method [18].

2.4. Immunohistochemistry Analysis. Immunohistochemical study for Dickkopf-1 was performed on formalin-fixed, paraffin-embedded, $4-\mu \mathrm{m}$-thick tissue sections using the avidin-biotin-peroxidase complex method. In brief, the sections were deparaffinized and dehydrated using a graded series of ethanol solutions. Endogenous peroxidase activity was halted through the administration of $0.3 \%$ hydrogen peroxidase and methanol for $20 \mathrm{~min}$. After having been 
TABLE 1: Correlations of Dickkopf-1 expression with the clinicopathological features of gastric cancer.

\begin{tabular}{|c|c|c|c|c|}
\hline \multirow{2}{*}{ Features } & \multirow{2}{*}{ No. of cases } & \multicolumn{2}{|c|}{ Dickkopf-1 expression } & \multirow{2}{*}{$P$} \\
\hline & & High & Low & \\
\hline Age (years) & 328 & $57.2 \pm 9.6$ & $61.9 \pm 11.8$ & NS \\
\hline \multicolumn{5}{|l|}{ Gender } \\
\hline Male & 235 & 133 & 102 & \multirow{2}{*}{ NS } \\
\hline Female & 93 & 62 & 31 & \\
\hline \multicolumn{5}{|l|}{ Tumor Location } \\
\hline Proximal & 42 & 27 & 15 & \multirow{3}{*}{ NS } \\
\hline Middle & 123 & 70 & 53 & \\
\hline Distal & 163 & 97 & 66 & \\
\hline \multicolumn{5}{|l|}{ Tumor size } \\
\hline$<5 \mathrm{~cm}$ & 192 & 116 & 76 & \multirow{2}{*}{ NS } \\
\hline$\geq 5 \mathrm{~cm}$ & 136 & 79 & 57 & \\
\hline \multicolumn{5}{|l|}{ Lauren classification } \\
\hline Intestinal & 168 & 100 & 68 & \multirow{2}{*}{ NS } \\
\hline Diffuse & 160 & 95 & 65 & \\
\hline \multicolumn{5}{|l|}{ Histology } \\
\hline Papillary adenocarcinoma & 12 & 5 & 7 & \multirow{4}{*}{ NS } \\
\hline Tubular adenocarcinoma & 245 & 158 & 87 & \\
\hline Mucinous adenocarcinoma & 22 & 12 & 10 & \\
\hline Signet-ring cell & 49 & 20 & 29 & \\
\hline \multicolumn{5}{|l|}{ Histologic differentiation } \\
\hline Well-moderately & 96 & 61 & 35 & \multirow{3}{*}{ NS } \\
\hline Poorly & 220 & 132 & 88 & \\
\hline Other & 3 & 2 & 1 & \\
\hline \multicolumn{5}{|l|}{ Invasion depth } \\
\hline $\mathrm{T} 1$ & 68 & 14 & 54 & \multirow{4}{*}{$<0.01$} \\
\hline $\mathrm{T} 2$ & 78 & 35 & 43 & \\
\hline $\mathrm{T} 3$ & 130 & 101 & 29 & \\
\hline $\mathrm{T} 4$ & 52 & 45 & 7 & \\
\hline \multicolumn{5}{|l|}{ TNM stages } \\
\hline I & 68 & 14 & 54 & \multirow{4}{*}{$<0.01$} \\
\hline II & 78 & 35 & 43 & \\
\hline III & 130 & 101 & 29 & \\
\hline IV & 52 & 45 & 7 & \\
\hline \multicolumn{5}{|l|}{ Vessel invasion } \\
\hline No & 201 & 95 & 106 & \multirow{2}{*}{$<0.01$} \\
\hline Yes & 127 & 100 & 27 & \\
\hline Lymphatic metastasis & & & & \\
\hline No & 126 & 45 & 81 & $<001$ \\
\hline Yes & 202 & 150 & 52 & $<0.01$ \\
\hline Regional lymph nodes & & & & \\
\hline PNO & 125 & 37 & 88 & \\
\hline PN1 & 102 & 69 & 33 & $<0.01$ \\
\hline PN2 & 75 & 66 & 9 & $<0.01$ \\
\hline PN3 & 26 & 23 & 3 & \\
\hline Distant metastasis & & & & \\
\hline No & 282 & 155 & 127 & $<0.01$ \\
\hline Yes & 46 & 40 & 6 & $<0.01$ \\
\hline
\end{tabular}

"NS" refers to no significance. 
rinsed in phosphate-buffered saline (PBS), the tissue sections were processed in a $0.01 \mathrm{M}$ citrate buffer $(\mathrm{pH}$ 6.0) inside a heat-resistant plastic container. Sections were then irradiated in a domestic microwave oven for $20 \mathrm{~min}$. The slides were allowed to cool at room temperature following microwave irradiation. After incubation with rabbit polyclonal primary antibody Dickkopf-1 (Santa Cruz Biotechnology, Santa Cruz, CA, USA, dilution $1: 60$ ), which was used in several previous studies [16, 19-21], for $2 \mathrm{~h}$ at room air temperature, staining was performed by labeled streptavidin-biotin method. Negative controls of immunohistochemical reactions included omission of the primary antibody. Normal human placenta was used as a positive control.

Following a hematoxylin counterstaining, immunostaining was scored by two independent experienced pathologists, who were blinded to the clinicopathological parameters and clinical outcomes of the patients. The scores of the two pathologists were compared, and any discrepant scores were trained through reexamining the stainings by both pathologists to achieve a consensus score. The number of positivestaining cells showing immunoreactivity of Dickkopf- 1 in ten representative microscopic fields was counted, and the percentage of positive cells was calculated. The percentage scoring of immunoreactive tumor cells was as follows: 0 (0\%), 1 (1-10\%), $2(11-50 \%)$, and $3(>50 \%)$. The staining intensity was visually scored and stratified as follows: 0 (negative), 1 (weak), 2 (moderate), and 3 (strong). A final score was obtained for each case by multiplying the percentage and the intensity score. Therefore, tumors with a multiplied score exceeding 4 (i.e., tumors with a moderate or strong staining intensity of $>10 \%$ of the tumor cells) were deemed to be showing high expression of Dickkopf-1; all other scores were considered to be low expression.

2.5. Statistical Analysis. The software of SPSS version 13.0 for Windows (SPSS Inc, IL, USA) was used for statistical analysis. Measurement data were analyzed using the Student's $t$-test, while categorical data were analyzed using $\chi^{2}$ or Fisher's exact tests. Survival curves were estimated using the KaplanMeier method and the log-rank test was used to compute differences between the curves. Multivariate analysis using the Cox proportional hazards regression model was performed to assess the prognostic value of protein expression levels. Correlation coefficients between Dickkopf-1 protein expression and clinicopathological findings were estimated using the Pearson correlation method. Differences were considered statistically significant when $P$ was less than 0.05 .

\section{Results}

3.1. Overexpression of Dickkopf-1 mRNA in Human Gastric Cancer Tissues. Real-time quantitative RT-PCR was performed to detect the expression of Dickkopf-1 mRNA in 20 pairs of human gastric cancer and adjacent noncancerous human gastric tissues. GAPDH gene was used as an internal control. Densitometric evaluation was used to compare mRNA levels among tissue samples. The expression level of Dickkopf-1 mRNA showed significant difference between



(a)



(c)

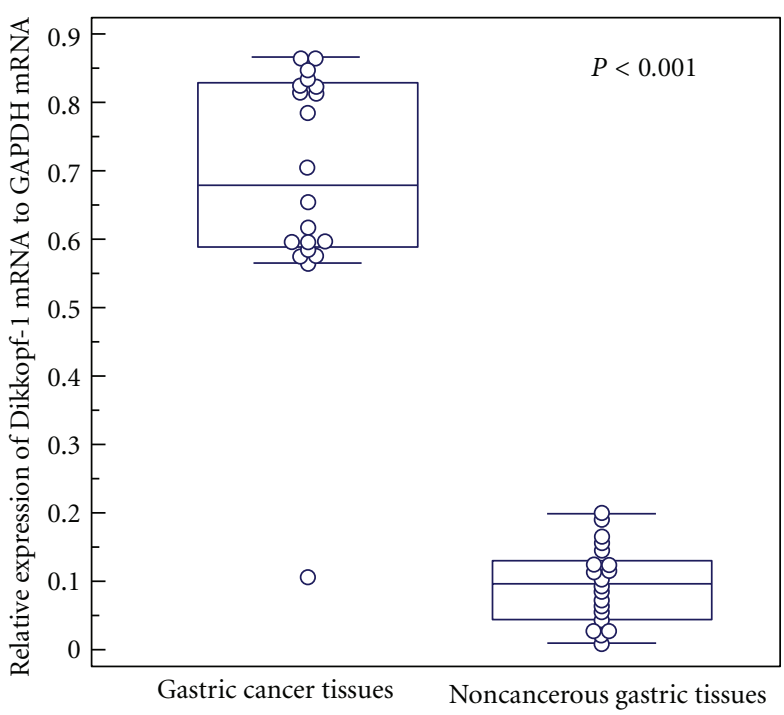

(b)

FIGURE 1: Real-time quantitative RT-PCR analysis of Dickkopf1 mRNA expression in 20 pairs of human gastric cancer and adjacent noncancerous human gastric tissues. (a) Gel images of electrophoresis. "N" refers to noncancerous gastric tissues; "GC" refers to gastric cancer tissues. (b) The average level of Dikkopf-1 mRNA expression in gastric cancer tissues was significantly higher than that in noncancerous gastric tissues $(P<0.001)$. GAPDH gene was used as an internal control. (c) The specificity of Dikkopf-1 antibody was analyzed by western blot testing. A single band of $35 \mathrm{kDa}$ was detected in gastric cancer tissues. $\beta$-actin antibody was used as control with the single band of $42 \mathrm{kDa}$.

gastric cancer tissues and corresponding noncancerous gastric tissues (Figure 1(a)). The average ratios of Dickkopf1 mRNA to GAPDH mRNA in gastric cancer tissues and noncancerous gastric tissues were $0.68 \pm 0.18$ and $0.09 \pm$ 0.05 , respectively (Figure 1(b)), which suggested that the expression of Dickkopf-1 mRNA was significantly higher in gastric cancer tissues than that in corresponding noncancerous gastric tissues $(P<0.001)$.

3.2. Immunohistochemical Findings of Dickkopf-1. The specificity of anti-Dickkopf-1 antibody was confirmed by Western blot analysis using lysates of Dickkopf-1-expressing gastric cancer tissues. As shown in Figure 1(c), a single band of Dickkopf-1 expression was detected, which was consistent with the results of Yamabuki et al. on lung and esophageal carcinoma cells [16].

A total of 328 pairs of gastric cancer and noncancerous human gastric tissues were evaluated for Dickkopf- 1 protein 

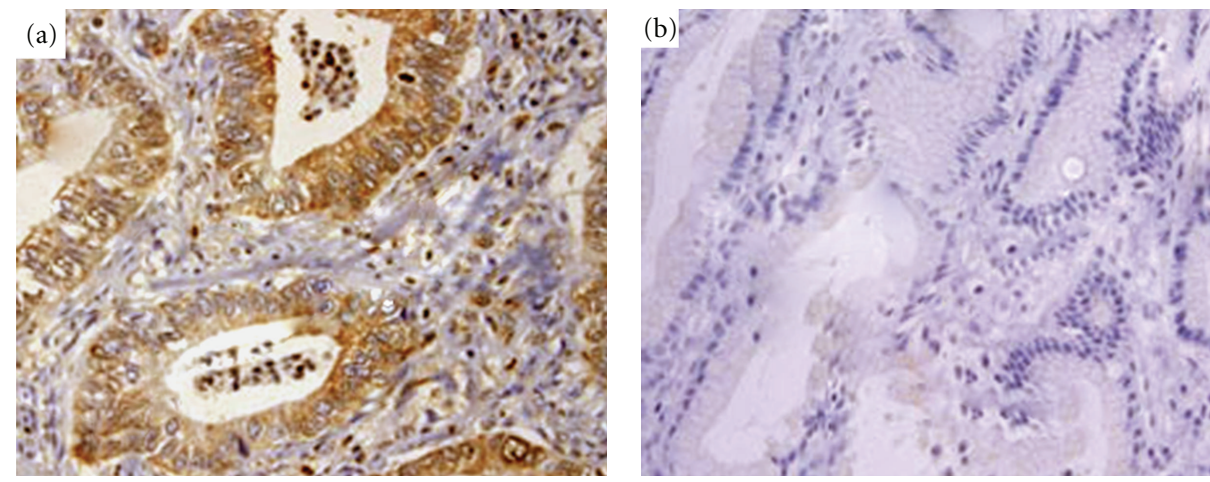

FIGURE 2: Dickkopf-1-expression by immunohistochemical staining (magnification $\times 400$ ). (a) Representative Dickkopf-1-positive gastric cancer showing staining mainly in the cytoplasm of tumor cells. (b) Representative Dickkopf-1 negative expression in noncancerous human gastric tissues.

expression by immunohistochemical analysis. High expression was detected in 195/328 (59.5\%) human gastric cancer cases and low expression in 133 (40.5\%). Dickkopf-1 was mainly localized in the cytoplasm, and less localized in nuclei of primary cancer cells (Figure 2(a)). In contrast, none of the noncancerous human gastric tissues showed significant level of immunohistochemical staining (Figure 2(b)).

\subsection{Overexpression of Dickkopf-1 and Clinicopathological Fea-} tures of Gastric Cancer. Positive expression of Dickkopf-1 correlated with depth of invasion, vessel invasion, lymph node and distant metastasis, and TNM stage (all $P<0.01$ ), but not with age, gender, tumor size, location, differentiation stage, or histological type (all $P>0.05$ ) (Table 1). Possible prognostic factors for gastric cancer were analyzed by Cox regression analysis. This showed that the depth of invasion $(P=0.02)$, lymph node $(P=0.01)$ and distant metastasis $(P=0.008)$, TNM stage $(P=0.006)$, and the level of Dickkopf-1 expression $(P=0.002)$ were all independent prognostic factors in patients with gastric cancer. However, the location of the tumor, tumor size, histological type, differentiation, and vessel invasion had no prognostic value.

3.4. Influence of the Dickkopf-1 Expression on Survival. For patients with stage I, II, or III disease, the 5-year survival rate for those with high Dickkopf-1 expression were significantly lower than in patients with low expression. For stage I, the cumulative 5 -year survival rate was $90.7 \%$ in the lowexpression group, but only $71.4 \%$ in the high-expression group $(P=0.001$, Figure $3(\mathrm{a}))$; for stage II, the cumulative 5 -year survival rate was $69.8 \%$ in the low-expression group, but only $54.3 \%$ in the high-expression group $(P=0.001$, Figure 3(b)); for stage III, the cumulative 5-year survival rate was $55.2 \%$ in the low-expression group, but only $21.8 \%$ in the high-expression group $(P=0.0001$, Figure $3(\mathrm{c}))$. For stage IV the expression of Dickkopf-1 did not correlate with the 5 -year survival rate $(14.3 \%$ in the low-expression group and $2.2 \%$ in the high-expression group; $P=0.5$ ).

\section{Discussion}

Gastric cancer is associated with a much shorter time to recurrence and a shorter survival period after recurrence. Because of the early metastasis and strong invasion, it is very important to estimate the malignant degree and invasion tendency of gastric cancer in order to guide clinical diagnosis and treatment of this disease. In the present study, immunohistochemistry was used to analyze the expression levels of Dickkopf-1 in 328 clinicopathologically characterized gastric cancer patients. The results showed that Dickkopf1 protein was significantly upregulated in gastric cancer tissues compared with normal gastric tissues, which was confirmed by real-time qRT-PCR analysis on the expression of Dickkopf-1 mRNA. In addition, high levels of Dickkopf1 expression in gastric cancer lesions were associated with depth of invasion, vessel invasion, lymph node and distant metastasis, and TNM stage. Furthermore, the up-regulation of Dickkopf-1 was an independent prognostic indicator for gastric cancer. Therefore, Dickkopf-1 may be a valuable diagnostic marker and therapeutic target for gastric cancer.

Several recent studies have demonstrated that Dickkopf-1 plays multiple biological roles in a variety of cancers. Gene expression profile analysis revealed that Dickkopf-1 was highly transactivated in the great majority of lung cancers and esophageal squamous cell carcinomas [16]. Overexpression of Dickkopf-1 has also been detected in human hepatoblastomas and Wilms' tumors [14]. In contrast, expression of the Dickkopf- 1 gene, a downstream target of $\beta$-catenin/TCF, decreases in human colon tumors, indicating its tumorsuppressing role in this neoplasia [22]. Recent evidence also suggests that Dickkopf-1 is a functional suppressor of HeLa cell transformation [23]. Human Dickkopf-1 was reported to be responsive to p53 although it has been shown to be induced by DNA damage and to sensitize to apoptosis in a p53-independent manner [24]. However, the involvement of Dickkopf-1 in gastric cancers has not been defined. In 2007, Sato et al. reported that Dickkopf methylation was frequently observed in gastric cancer cell lines [25]. But Shi et al. in 2009 demonstrated that serum concentrations of Dickkopf-1 were decreased significantly in groups of patients 


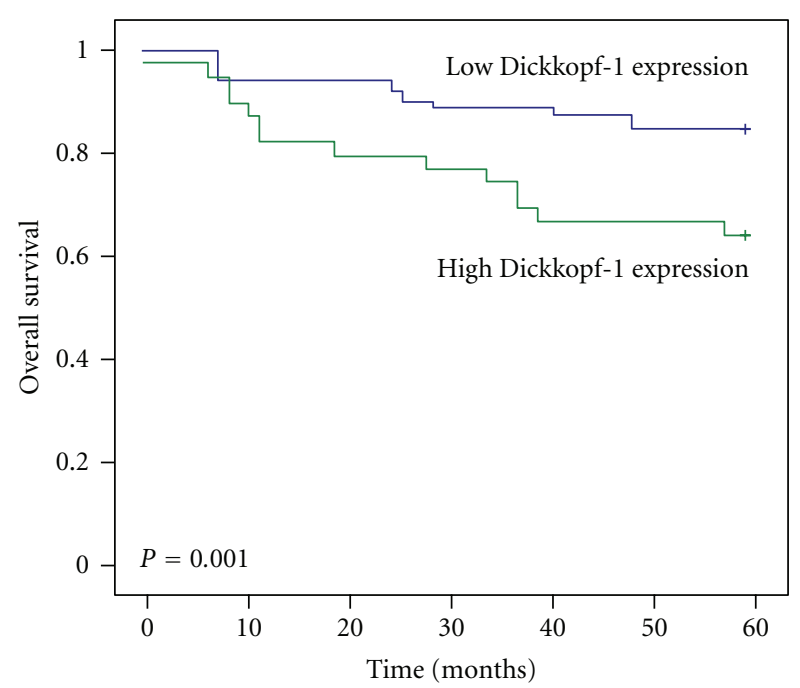

(a)

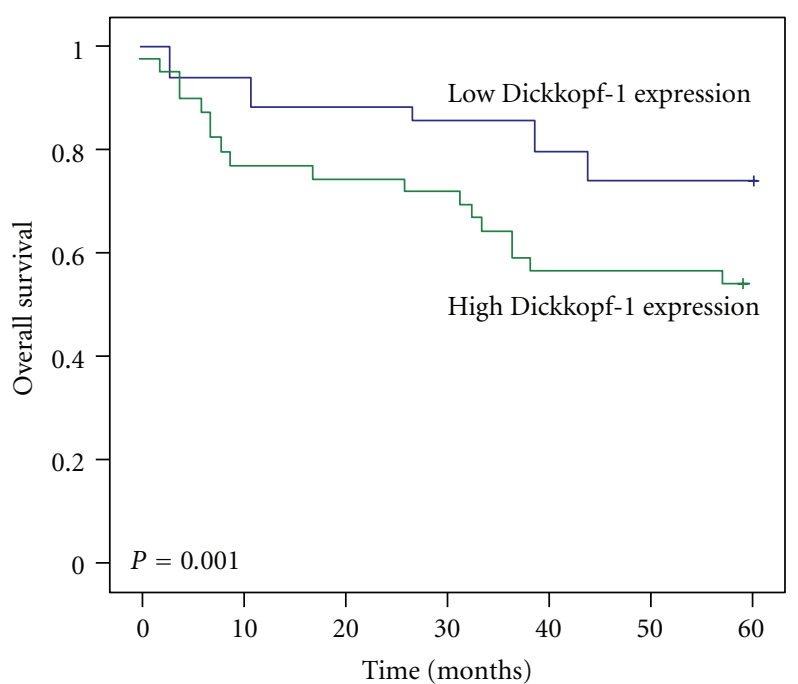

(b)

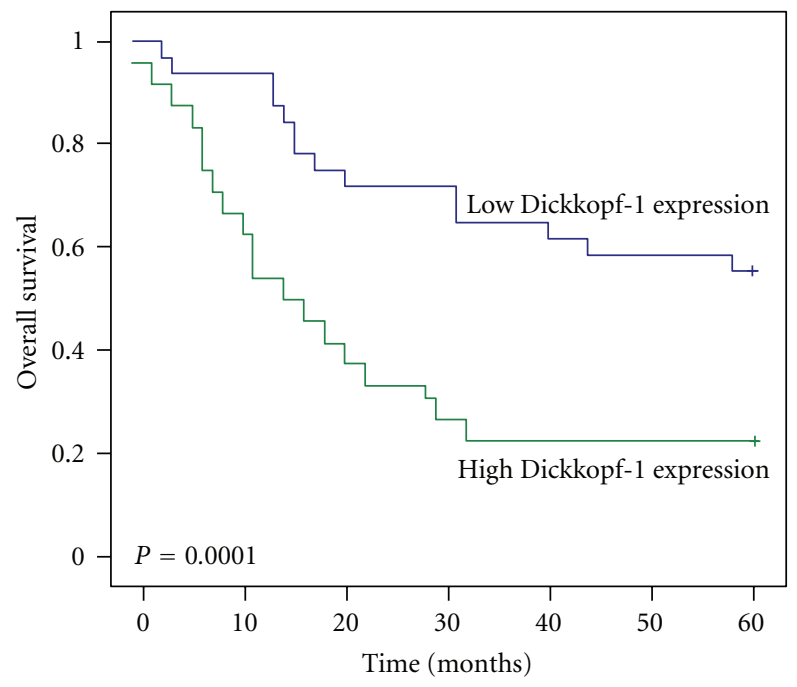

(c)

Figure 3: The Kaplan-Meier curves with univariate analyses (log-rank) for patients with low Dickkopf-1 expression versus high Dickkopf-1 expression tumors in all gastric cancers in stage I (a), II (b), and III (c). In stages I, II, and III gastric cancers, the 5-year survival rate of patients with a high expression of Dickkopf-1 was significantly lower than that in patients with low expression.

with gastric cancer compared with healthy controls [26]. Additionally, these previous studies could not clarify the clinical impact of Dickkopf-1 expression or the prognostic value for gastric cancer. Therefore, this is the first report to determine the correlation between Dickkopf- 1 expression and clinical factors in gastric cancer. Our results showed that Dickkopf-1 was upregulated in gastric cancer tissues compared with noncancerous tissues and the high or low expression of Dickkopf-1 in gastric cancer directly affected clinical factors. This discrepancy with the previous study of Shi et al. [26] may be due to the small numbers used in their study.

With respect to the results of survival analysis, in patients with stage I, II, and III gastric cancer, the 5-year survival rate for those with high Dickkopf-1 expression was significantly lower than that of patients with low expression. However, for stage IV, expression did not correlate with the 5-year survival rate. Multivariate analysis suggested that the depth of invasion, lymph node and distant metastasis, TNM stage, and Dickkopf-1 up-regulation were independent prognostic indicators for gastric cancer. It is known that Dickkopf-1 expression correlates with a reduction in disease-free survival and is an independent predictor of poor prognosis in human esophageal squamous cell carcinoma [19]. In ovarian serous carcinoma, Wang and Zhang also showed that the level of Dickkopf- 1 expression is associated with adverse outcomes. Dickkopf-1, P-JNK1, and the coexpression of Dickkopf-1 and P-JNK1 were all unfavorable prognosis factors for ovarian serous carcinoma patients. Dickkopf-1, alone or combined with P-JNK1, was an independent predictor for the 5-year survival [17]. Additionally, Dickkopf-1 secreted and stably expressed in cerebral fluids can also be applicable to detect 
presence of glioblastoma and to develop novel prognostic treatments [20].

In conclusion, our data showed that a subset of patients with gastric cancer had overexpression of Dickkopf-1, which was associated with an aggressive clinical course and poor overall survival. Therefore, Dickkopf-1 may play a significant role in the progression of gastric cancer, which was consistent with most other cancers. In addition, such information may direct us toward novel therapeutic and prognostic possibilities for treating gastric cancer and improving patient outcomes. This is the first report to suggest a relationship between Dickkopf-1 and prognosis in patients with gastric cancer, and further prospective analysis would be worth doing.

\section{References}

[1] C.-W. Tseng, C.-C. Lin, C.-N. Chen, H.-C. Huang, and H.-F. Juan, "Integrative network analysis reveals active microRNAs and their functions in gastric cancer," BMC Systems Biology, vol. 5, article 99, 2011.

[2] P. Jian, T. Yanfang, Z. Zhuan, W. Jian, Z. Xueming, and N. Jian, "MMP28 (epilysin) as a novel promoter of invasion and metastasis in gastric cancer," BMC Cancer, vol. 11, article 200, 2011.

[3] A. Atmaca, C. Pauligk, K. Steinmetz, H.-M. Altmannsberger, E. Jäger, and S.-E. Al-Batran, "Prognostic impact of phosphorylated mitogen-activated protein kinase expression in patients with metastatic gastric cancer," Oncology, vol. 80, no. 1-2, pp. 130-134, 2011.

[4] Y. Katoh and M. Katoh, "Comparative genomics on DKK2 and DKK4 orthologs," International Journal of Molecular Medicine, vol. 16, no. 3, pp. 477-481, 2005.

[5] C. Niehrs, "Function and biological roles of the Dickkopf family of Wnt modulators," Oncogene, vol. 25, no. 57, pp. 7469$7481,2006$.

[6] F. Kuhnert, C. R. Davis, H. T. Wang et al., "Essential requirement for Wnt signaling in proliferation of adult small intestine and colon revealed by adenoviral expression of Dickkopf-1," Proceedings of the National Academy of Sciences of the United States of America, vol. 101, no. 1, pp. 266-271, 2004.

[7] S. Yaccoby, W. Ling, F. Zhan, R. Walker, B. Barlogie, and J. D. Shaughnessy, "Antibody-based inhibition of DKK1 suppresses tumor-induced bone resorption and multiple myeloma growth in vivo," Blood, vol. 109, no. 5, pp. 2106$2111,2007$.

[8] K. Ogoshi, A. Kasamatsu, M. Iyoda et al., "Dickkopf-1 in human oral cancer," International Journal of Oncology, vol. 39, no. 2, pp. 329-336, 2011.

[9] R. Feldmann, M. Schierl, A. M. Fink, P.-G. Sator, J. Maiweg, and A. Steiner, "Serum levels of glycoprotein Dickkopf-1 in patients with cutaneous malignant melanoma: a prospective pilot study," Dermatology, vol. 222, no. 2, pp. 171-175, 2011.

[10] A. M. Mikheev, S. A. Mikheeva, R. Rostomily, and H. Zarbl, "Dickkopf-1 activates cell death in MDA-MB435 melanoma cells," Biochemical and Biophysical Research Communications, vol. 352, no. 3, pp. 675-680, 2007.

[11] S. Kuphal, S. Lodermeyer, F. Bataille, M. Schuierer, B. H. Hoang, and A. K. Bosserhoff, "Expression of Dickkopf genes is strongly reduced in malignant melanoma," Oncogene, vol. 25, no. 36, pp. 5027-5036, 2006.
[12] A. Y. Lee, B. He, L. You et al., "Dickkopf-1 antagonizes Wnt signaling independent of $\beta$-catenin in human mesothelioma," Biochemical and Biophysical Research Communications, vol. 323, no. 4, pp. 1246-1250, 2004.

[13] A. M. Mikheev, S. A. Mikheeva, J. P. Maxwell et al., "Dickkopf1 mediated tumor suppression in human breast carcinoma cells," Breast Cancer Research and Treatment, vol. 112, no. 2, pp. 263-273, 2008.

[14] O. Wirths, A. Waha, S. Weggen et al., "Overexpression of human Dickkopf-1, an antagonist of wingless/WNT signaling, in human hepatoblastomas and Wilms' tumors," Laboratory Investigation, vol. 83, no. 3, pp. 429-434, 2003.

[15] M. A. Forget, S. Turcotte, D. Beauseigle et al., "The Wnt pathway regulator DKK1 is preferentially expressed in hormoneresistant breast tumours and in some common cancer types," British Journal of Cancer, vol. 96, no. 4, pp. 646-653, 2007.

[16] T. Yamabuki, A. Takano, S. Hayama et al., "Dikkopf-1 as a novel serologic and prognostic biomarker for lung and esophageal carcinomas," Cancer Research, vol. 67, no. 6, pp. 2517-2525, 2007.

[17] S. Wang and S. Zhang, "Dickkopf-1 is frequently overexpressed in ovarian serous carcinoma and involved in tumor invasion," Clinical and Experimental Metastasis, vol. 28, no. 6, pp. 581-591, 2011.

[18] H. Shen, Y. Fan, Y. Xi, F. J. Burczynski, P. Li, and Y. Gong, "Increased expression of cystic fibrosis transmembrane conductance regulator in rat liver after common bile duct ligation," Journal of Cellular Physiology, vol. 203, no. 3, pp. 599603, 2005.

[19] T. Makino, M. Yamasaki, I. Takemasa et al., "Dickkopf1 expression as a marker for predicting clinical outcome in esophageal squamous cell carcinoma," Annals of Surgical Oncology, vol. 16, no. 7, pp. 2058-2064, 2009.

[20] Y. Zhou, F. Liu, Q. Xu, and X. Wang, "Analysis of the expression profile of Dickkopf-1 gene in human glioma and the association with tumor malignancy," Journal of Experimental and Clinical Cancer Research, vol. 29, no. 1, article 138, 2010.

[21] L. H. Weng, C. J. Wang, J. Y. Ko, Y. C. Sun, Y. S. Su, and F. S. Wang, "Inflammation induction of Dickkopf-1 mediates chondrocyte apoptosis in osteoarthritic joint," Osteoarthritis and Cartilage, vol. 17, no. 7, pp. 933-943, 2009.

[22] J. M. González-Sancho, O. Aguilera, J. M. García et al., “The Wnt antagonist DICKKOPF-1 gene is a downstream target of $\beta$-catenin/TCF and is downregulated in human colon cancer," Oncogene, vol. 24, no. 6, pp. 1098-1103, 2005.

[23] A. M. Mikheev, S. A. Mikheeva, B. Liu, P. Cohen, and H. Zarbl, "A functional genomics approach for the identification of putative tumor suppressor genes: Dickkopf-1 as suppressor of HeLa cell transformation," Carcinogenesis, vol. 25, no. 1, pp. 47-59, 2004.

[24] J. Shou, F. Ali-Osman, A. S. Multani, S. Pathak, P. Fedi, and K. S. Srivenugopal, "Human Dkk-1, a gene encoding a Wnt antagonist, responds to DNA damage and its overexpression sensitizes brain tumor cells to apoptosis following alkylation damage of DNA," Oncogene, vol. 21, no. 6, pp. 878-889, 2002.

[25] H. Sato, H. Suzuki, M. Toyota et al., "Frequent epigenetic inactivation of DICKKOPF family genes in human gastrointestinal tumors," Carcinogenesis, vol. 28, no. 12, pp. 2459-2466, 2007.

[26] L. S. Shi, G. Huang, B. Yu, and X. Q. Wen, "Clinical significance and prognostic value of serum Dickkopf-1 concentrations in patients with lung cancer," Clinical Chemistry, vol. 55, no. 9, pp. 1656-1664, 2009. 


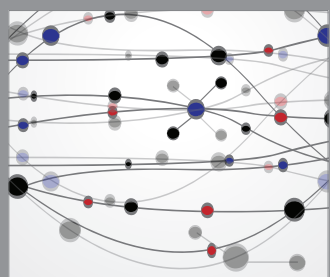

The Scientific World Journal
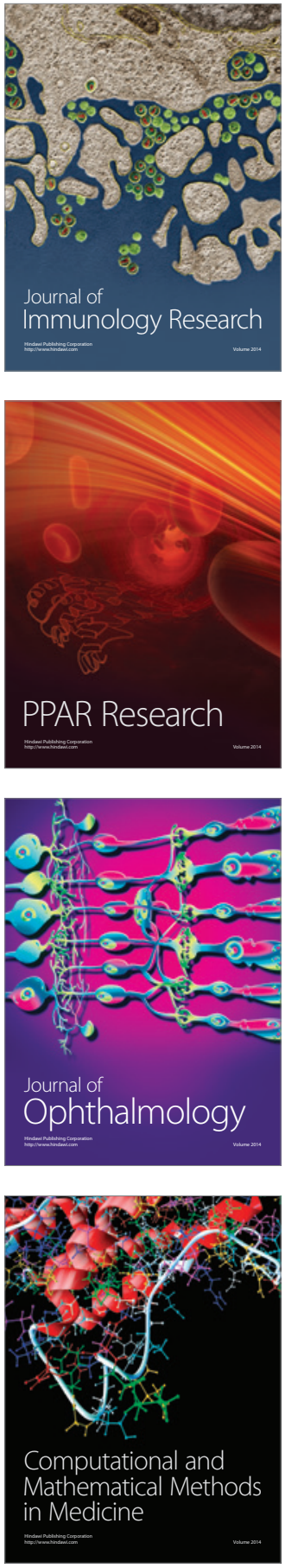

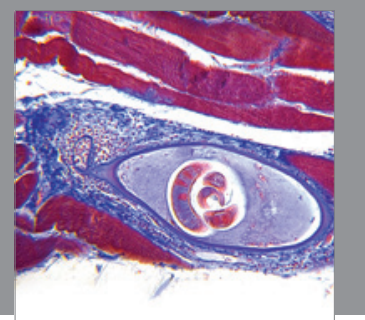

Gastroenterology

Research and Practice
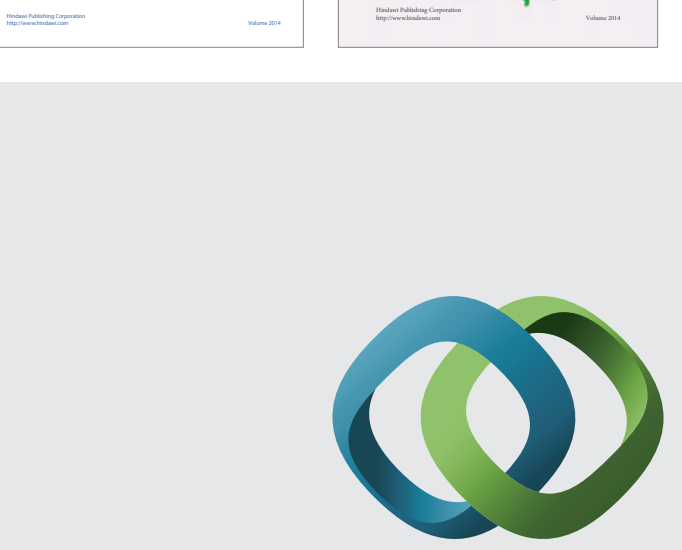

\section{Hindawi}

Submit your manuscripts at

http://www.hindawi.com
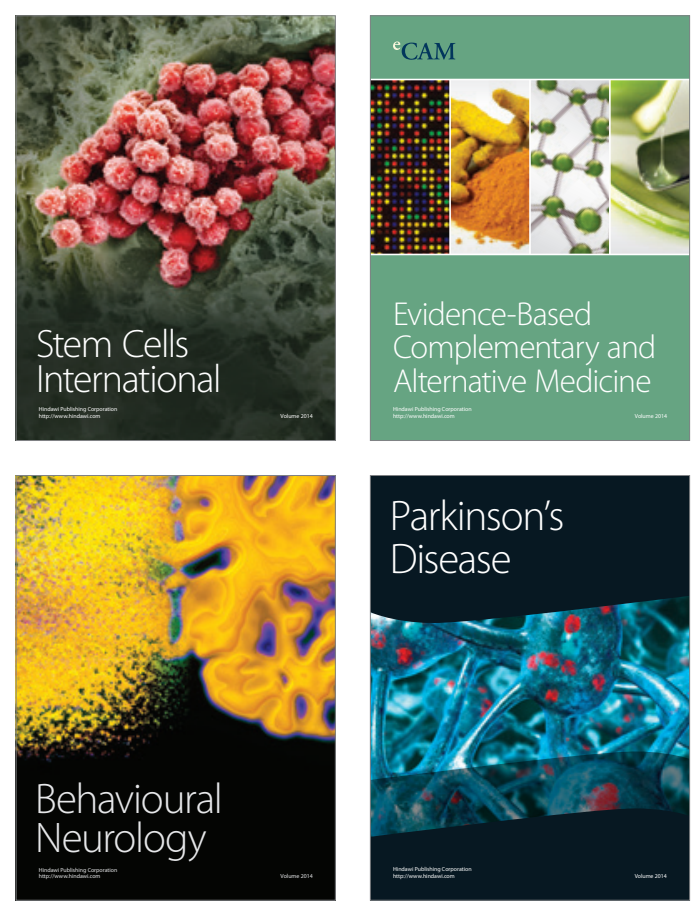

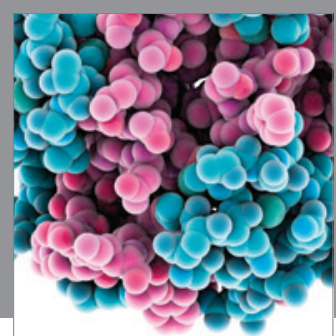

Journal of
Diabetes Research

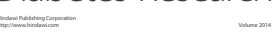

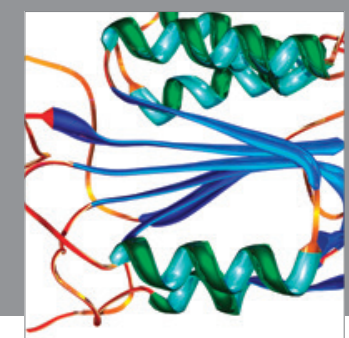

Disease Markers
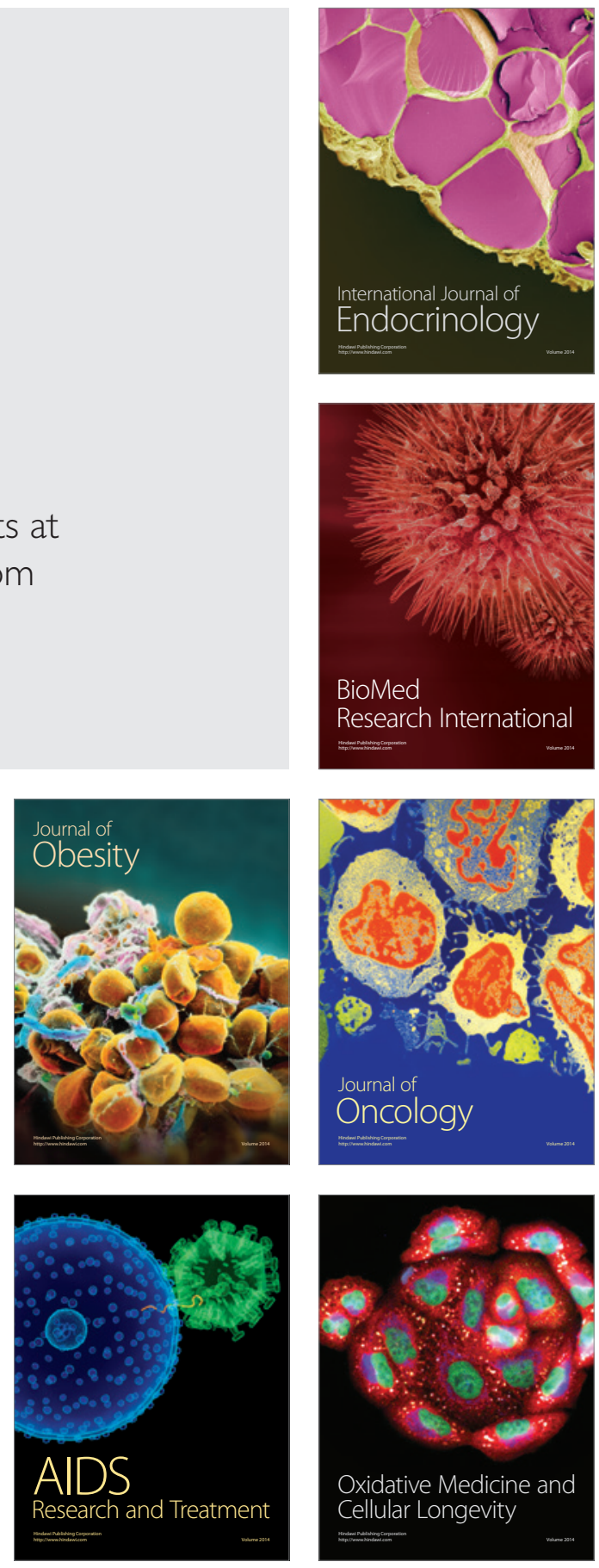